\title{
ANÁLISE MICROCLIMÁTICA DAS DIFERENTES TIPOLOGIAS DE FLORESTA URBANA DE CURITIBA
}

\author{
Angeline Martini ${ }^{1 *}$, Daniela Biondi ${ }^{2}$, Antonio Carlos Batista $^{2}$, Demóstenes Ferreira da Silva Filho ${ }^{3}$ \\ ${ }^{1 *}$ Universidade Federal de Viçosa, Departamento de Engenharia Florestal, Viçosa, Minas Gerais, Brasil - martini@ufv.br \\ ${ }^{2}$ Universidade Federal do Paraná, Departamento de Ciências Florestais, Curitiba, Paraná, Brasil - dbiondi@ufpr.br; batistaufpr@ufpr.br \\ ${ }^{3}$ Universidade de São Paulo, Departamento de Ciências Florestais, Piracicaba, São Paulo, Brasil - dfilho@ usp.br
}

Recebido para publicação: 01/12/2016 - Aceito para publicação: 13/06/2017

\begin{abstract}
Resumo
A vegetação é um dos elementos essenciais para garantir a qualidade de vida nas cidades, devido os inúmeros benefícios que proporciona. Esta pesquisa teve como objetivo analisar a variação da temperatura e umidade relativa do ar em diferentes tipologias de florestas urbanas de Curitiba durante o verão e inverno. Para isso, foram selecionadas três áreas de cada tipologia de floresta urbana: Remanescente Florestal, Área Verde Antiga, Área Verde Moderna, Arborização de Rua e Árvore isolada. O microclima dessas áreas foi analisado por meio das variáveis temperatura e umidade relativa do ar, coletadas com registradores data logger modelo Hobo ${ }^{\circledR}$, instalados em mini abrigos meteorológicos. O monitoramento das variáveis meteorológicas foi realizado simultaneamente em todas as áreas selecionadas, durante 48 horas, com tomada de dados contínuo em intervalos de 1 minuto, iniciando-se às $12 \mathrm{~h}$, nos meses de fevereiro e julho. Os resultados indicaram diferença estatística entre o remanescente florestal e as demais tipologias de floresta urbana, para ambas as variáveis e estações do ano. A temperatura média do ar no remanescente florestal foi menor do que nas demais áreas, enquanto a umidade relativa foi maior. Quando comparadas com o remanescente, a tipologia árvore isolada foi a que apresentou maior diferença de temperatura, registrando $1,22^{\circ} \mathrm{C}$ a menos, seguida por arborização de rua $\left(1,08^{\circ} \mathrm{C}\right)$, área verde antiga $\left(0,98^{\circ} \mathrm{C}\right)$ e área verde moderna $\left(0,68^{\circ} \mathrm{C}\right)$. Conclui-se que as diferentes tipologias de floresta urbana apresentam microclimas distintos, sendo que o Remanescente Florestal é o que proporciona valores menores de temperatura e maiores de umidade relativa.

Palavras-chave: Vegetação; temperatura do ar; umidade relativa do ar; verão; inverno.
\end{abstract}

\begin{abstract}
Microclimate analysis of different types of urban forest in Curitiba city. The vegetation is essential to ensure the quality of life in cities, due to the numerous benefits it provides, especially in climatic aspects. This study aimed to characterize the microclimate of the different types of urban forest existing in Curitiba, PR, in summer and winter. For this, three areas were selected for each type of urban forest: remaining forest, old green area, modern green area, street trees and single tree. The microclimate these areas was analyzed by varying temperature $\left({ }^{\circ} \mathrm{C}\right)$ and relative humidity of air $(\%)$, collected by data logger Hobo ${ }^{\circledR}$ model, installed in mini-shelters for 48 hours, with continuous taken at intervals of 1 minutes, starting at $12 \mathrm{~h}$, in February and July. The results showed no statistical difference between the remaining forest and other types of urban forest, for both variables and seasons. The average air temperature in the remaining forest was lower than in other areas, while the relative humidity was higher. When compared with the remaining, to single tree was the typology that showed the largest temperature difference $\left(1.22{ }^{\circ} \mathrm{C}\right)$, followed by street trees $\left(1.08{ }^{\circ} \mathrm{C}\right)$, old green area $\left(0.98^{\circ} \mathrm{C}\right)$ and modern green area $\left(0.68^{\circ} \mathrm{C}\right)$. It is concluded that the different types of urban forest have different microclimates, and the remaining forest is what gives lower values of temperature and higher relative humidity.
\end{abstract}

Keywords: Vegetation; air temperature; relative humidity; summer; winter.

\section{INTRODUÇÃO}

A relação equilibrada entre a natureza e a urbanização é amplamente aceita e inevitavelmente induz ao desejo da sociedade por árvores em ambientes urbanos (RASKOVIC; DECKER, 2015). Há indícios crescentes de que a exposição à natureza aumenta os recursos necessários para gerenciar as demandas e pressões da vida moderna, responsáveis por alguns dos problemas de saúde mais ameaçadores da atualidade (JIANG et al., 2014). Segundo esses autores, a criação de ambientes mais arborizados é uma forma eficaz de ajudar na redução do estresse da população, podendo reduzir muitas doenças que o acompanham, como doença cardiovascular, acidente vascular cerebral, depressão e asma.

FLORESTA, Curitiba, PR, v. 47, n. 2, p. 137 - 144, abr. / jun. 2017.

Martini, A. et al.

ISSN eletrônico 1982-4688

DOI: $10.5380 /$ rf.v47i1.49518 
Aliado a isso, a mudança climática global, também passou a gerar novos desafios e uma razão extra para otimizar o planejamento e gestão das áreas verdes urbanas (JIN et al., 2015). O aumento da temperatura global reconhecido durante as últimas décadas não foi apenas uma ideia simples ou abstrata, pois as temperaturas mais elevadas contribuíram para ondas mais intensas de calor, secas e tempestades (HEINL et al., 2015). Muitos habitantes das cidades em todo o mundo sofrem de problemas de saúde e desconforto causados por sobreaquecimento das zonas urbanas, e há evidências convincentes de que esses problemas serão intensificados pela mudança climática global (BROWN et al., 2015).

O clima é um fator importante, responsável pela mudança das paisagens e diversidade biológica na Terra. Nas cidades pode influenciar no desenvolvimento de tipologias e variações arquitetônicas, bem como em diferentes hábitos e costumes (BASSO; CORRÊA, 2014). Dentre as várias opções para promover refrigeração às cidades, a melhor já documentada é a criação de parques urbanos e espaços verdes, que têm o potencial de proporcionar ambientes termicamente confortáveis e reduzir a vulnerabilidade ao estresse térmico (BROWN et al., 2015).

Pesquisas têm sido dedicadas à avaliação da vegetação urbana, especialmente no contexto de sustentabilidade, aceleração da urbanização e qualidade de vida (RASKOVIC; DECKER, 2015). Além de ser uma estratégia de adaptação para lidar com as mudanças climáticas futuras, a presença de áreas vegetadas na cidade atua na mitigação dos efeitos das ilhas de calor urbana (KONG et al., 2014). Pois quando a vegetação é bem distribuída, o balanço de energia de toda a cidade pode ser modificado pela adição de mais superfícies evapotranspirativas, pois uma maior quantidade de radiação absorvida pode ser utilizada na forma de calor latente e a temperatura urbana pode ser reduzida (YU; HIEN, 2006).

A vegetação, independente da forma como se apresenta (arborização de ruas ou áreas verdes), possibilita a criação de microclimas urbanos diferenciados por meio do sombreamento, da redução da velocidade dos ventos, da proteção solar ao ambiente urbano edificado, da redução das temperaturas urbanas, evapotranspiração e retenção de umidade do solo e do ar (BASSO; CORREA, 2014). Pode ainda favorecer a habitabilidade das cidades, melhorando a paisagem, qualidade ambiental, saúde das pessoas e a própria qualidade de vida (JIN et al., 2015).

As árvores podem reduzir as temperaturas porque interceptam a radiação solar e sombreiam construções e outras superfícies. (ADAMNS; SMITH, 2014). Suas folhas possuem baixo índice de reflexão, absorvem a radiação solar incidente e bloqueiam boa parte da radiação solar direta (BASSO; CORREA, 2014). Consequentemente, a vegetação modifica a temperatura da superfície que atinge também a temperatura do ar, devido às alterações na geometria e propriedades radiativas da cobertura do solo (SHASHUA-BAR et al., 2010). Além disso, as árvores transformam uma pequena parte da radiação solar absorvida pela fotossíntese em calor latente (evapotranspiração), evitando que seja convertida em energia térmica (CHEN et al., 2014).

As áreas urbanas com vegetação proporcionam microclimas mais frios e criam ilhas de frescor urbanas localizadas (KONG et al., 2014), que são importantes para a saúde humana e sustentabilidade das cidades (CHEN et al., 2014). Por isso, várias cidades ao redor do mundo estão buscando aumentar a área verde ou cobertura de vegetação como uma forma de gerir o calor urbano, melhorando simultaneamente a beleza, a biodiversidade e o valor recreativo (ADAMNS; SMITH, 2014).

Segundo Jiang et al. (2015), essa ascensão da vegetação urbana ocorrida nas cidades nesta última década é uma forma de melhorar a paisagem, a habitabilidade das cidades, as condições ambientais e econômicas, a qualidade de vida e a saúde dos cidadãos. Nota-se, portanto, que nas cidades existem diversos tipos de áreas verdes, referidas aqui como floresta urbana, as quais desenvolvem diversas funções de acordo com a sua finalidade e grau de conservação. (ARAÚJO et al., 2015).

A cidade de Curitiba é destaque nacional pela quantidade e distribuição da vegetação urbana, além disso o município apresenta aspectos interessantes e características bem definidas para estudos de clima urbano, devido aos diferentes usos do solo, ordenados pelo zoneamento que estabelece parâmetros de ocupação (LEAL et al., 2015).

Neste contexto, o objetivo desta pesquisa foi analisar a variação da temperatura e umidade relativa do ar em diferentes tipologias de florestas urbanas de Curitiba durante o verão e o inverno, admitindo-se a hipótese de que a floresta urbana influencia na melhoria microclimática da cidade e que as diferentes tipologias proporcionam microclimas distintos.

\section{MATERIAL E MÉTODOS}

A pesquisa foi realizada na cidade de Curitiba, capital do estado do Paraná, localizada na região sul do Brasil a 934,6 m de altitude média. Segundo a classificação de Köppen, o clima de Curitiba é do tipo Cfb, 
subtropical úmido, oceânico, sem estação seca, com verão temperado (ALVARES et al., 2014). O verão é ameno (com temperaturas médias de $\left.20,5^{\circ} \mathrm{C}\right)$ e o inverno moderado $\left(13,0^{\circ} \mathrm{C}\right.$ em média) com alguns dias mais rigorosos. A precipitação média anual é de $1.550 \mathrm{~mm}$, concentrado nos meses de verão, e tendo como os meses mais secos julho e agosto (ALVARES et al., 2014).

Para a realização desta pesquisa foram selecionadas as tipologias de florestas urbanas mais frequentes nas cidades brasileiras, que são: Remanescente Florestal, Área Verde com Paisagismo e Arborização de Ruas. Ao longo do processo de seleção constatou-se a necessidade de dividir as três tipologias pré-estabelecidas em cinco. Isto porque na cidade de Curitiba, as áreas verdes com paisagismo e a própria arborização de ruas apresentam arranjos diferenciados entre si. Desta forma, as tipologias de floresta urbana adotadas nesta pesquisa foram:

a) Remanescente Florestal - área de cobertura arbórea formada por remanescente de Floresta Ombrófila Mista (Floresta de Araucária), localizada em parques, bosques e RPPNMs da cidade.

b) Área Verde Antiga - área de cobertura arbórea composta por agrupamentos de árvores implantadas com paisagismo Eclético, caracterizada pelo predomínio de árvores de grande porte e grande quantidade de caminhos e pavimentação, podendo ser parques e praças da cidade.

c) Área Verde Moderna - área de cobertura arbórea composta por agrupamentos de árvores implantadas com paisagismo Moderno, caracterizada principalmente pelo predomínio de gramado sob as árvores, podendo ser parques, praças, jardinetes, núcleos ambientais, largos, jardim ambiental e eixos de animação da cidade.

d) Arborização de Rua - área de cobertura arbórea contínua composta por agrupamentos de árvores em plantio linear, acompanhando o sistema viário.

e) Árvore isolada - área de cobertura arbórea composta por um único indivíduo arbóreo, plantado no sistema viário de forma espaçada, não seguindo um padrão da cidade.

A procura pelas áreas se restringiu a porção central da cidade, denominada administrativamente como Regional Matriz, em vista de melhor caracterizar o ambiente urbano consolidado. Tendo em vista uma melhor representatividade das tipologias de floresta urbana, levando-se em conta o tamanho e composição arbórea dos locais, foram selecionadas três áreas para cada tipologia de floresta urbana, totalizando assim 15 locais de monitoramento.

O microclima das diferentes tipologias de floresta urbana foi analisado mediante a coleta de dados meteorológicos a partir do método de pontos fixos. Este método consiste na alocação de equipamentos meteorológicos em qualquer área de uma cidade, neste caso, nas diferentes tipologias de floresta urbana selecionadas (Figura 1): Remanescente Florestal - Parque Natural Municipal Barigüi, Bosque Gutierrez e Bosque João Paulo II; Área Verde Antiga - Passeio Público, Praça Eufrásio Correia e Praça Carlos Gomes; Área Verde Moderna - Praça Nossa Senhora de Salette, Praça Alfredo Andersen e Jardinete Henrique Knopholz; Arborização de Rua - R. Ângelo Lopes, R. Brigadeiro Franco e R. Guaratuba; Árvore isolada - Lagerstroemia indica (extremosa), Lafoensia pacari (dedaleiro) e Handroanthus chrysotrichus (ipê-amarelo-miúdo).

O monitoramento das variáveis meteorológicas foi realizado simultaneamente em todas as áreas selecionadas, entre os dias 20 e 22 de fevereiro de 2014 (verão) e 28 e 30 de julho de 2014 (inverno). As datas foram definidas com base no histórico climático da cidade, onde se contatou que fevereiro é o mês mais quente e julho o mês mais frio. A partir da definição do mês, buscou-se nas previsões do tempo o dia mais adequado, sem previsões de chuva e característico das estações.

O equipamento utilizado neste método foi o registrador modelo Hobo® Data Logger RH \& Temp, devidamente protegido por um mini-abrigo meteorológico. Estes equipamentos foram previamente numerados e programados no software BoxCarß Pro 4. Após a programação foram fixados nos mini-abrigos, já prontos para serem levados a campo. Os mini-abrigos foram confeccionados em tubos de PVC, com $150 \mathrm{~mm}$ de comprimento e $100 \mathrm{~mm}$ de diâmetro, apresentando aberturas nas laterais e revestidos externamente com papel alumínio.

A instalação foi realizada na manhã do dia anterior à data de coleta, por dois pesquisadores, com o auxílio de uma escada extensível. O tempo médio para a instalação dos dezesseis mini-abrigos meteorológicos foi de quatro horas. Os mini-abrigos foram fixados com fita abraçadeira de nylon, a $4 \mathrm{~m}$ de altura, no tronco da árvore posicionada na porção central de cada tipologia de floresta urbana. A abertura da ventilação do miniabrigo foi direcionada para a posição nordeste.

Por questões de segurança e outras possíveis interferências humanas, a coleta das variáveis meteorológicas teve duração de 48 horas, com tomada contínua em intervalos de 1 minuto, iniciando-se às $12 \mathrm{~h}$ e totalizando 2882 leituras. Os dias foram caracterizados como de céu limpo e sem previsão de chuva.

O microclima proporcionado pelas diferentes tipologias de floresta foi analisado com os dados meteorológicos coletados a partir do método de pontos fixos, o que permitiu analisar duas variáveis: temperatura $\left({ }^{\circ} \mathrm{C}\right)$ e umidade relativa do ar $(\%)$.

FLORESTA, Curitiba, PR, v. 47, n. 2, p. 137 - 144, abr. / jun. 2017.

Martini, A. et al.

ISSN eletrônico 1982-4688

DOI: $10.5380 /$ rf.v47i1.49518 
Um panorama geral das variáveis meteorológicas foi elaborado a partir dos dados coletados a cada minuto, juntando as informações do verão e inverno. Com estas informações elaborou-se um delineamento estatístico em blocos ao acaso (três áreas de cada tipologia), no qual os tratamentos foram as diferentes tipologias de floresta urbana: Remanescente florestal, Área verde Antiga, Área Verde Moderna, Arborização de Rua e Árvore Isolada. A comparação das médias foi realizada pelo teste Student Newman Keuls (SNK) a 95\% de significância. Tendo em vista, as possíveis diferenças entre as estações, esta mesma análise foi realizada também separadamente, para as estações do verão e do inverno.
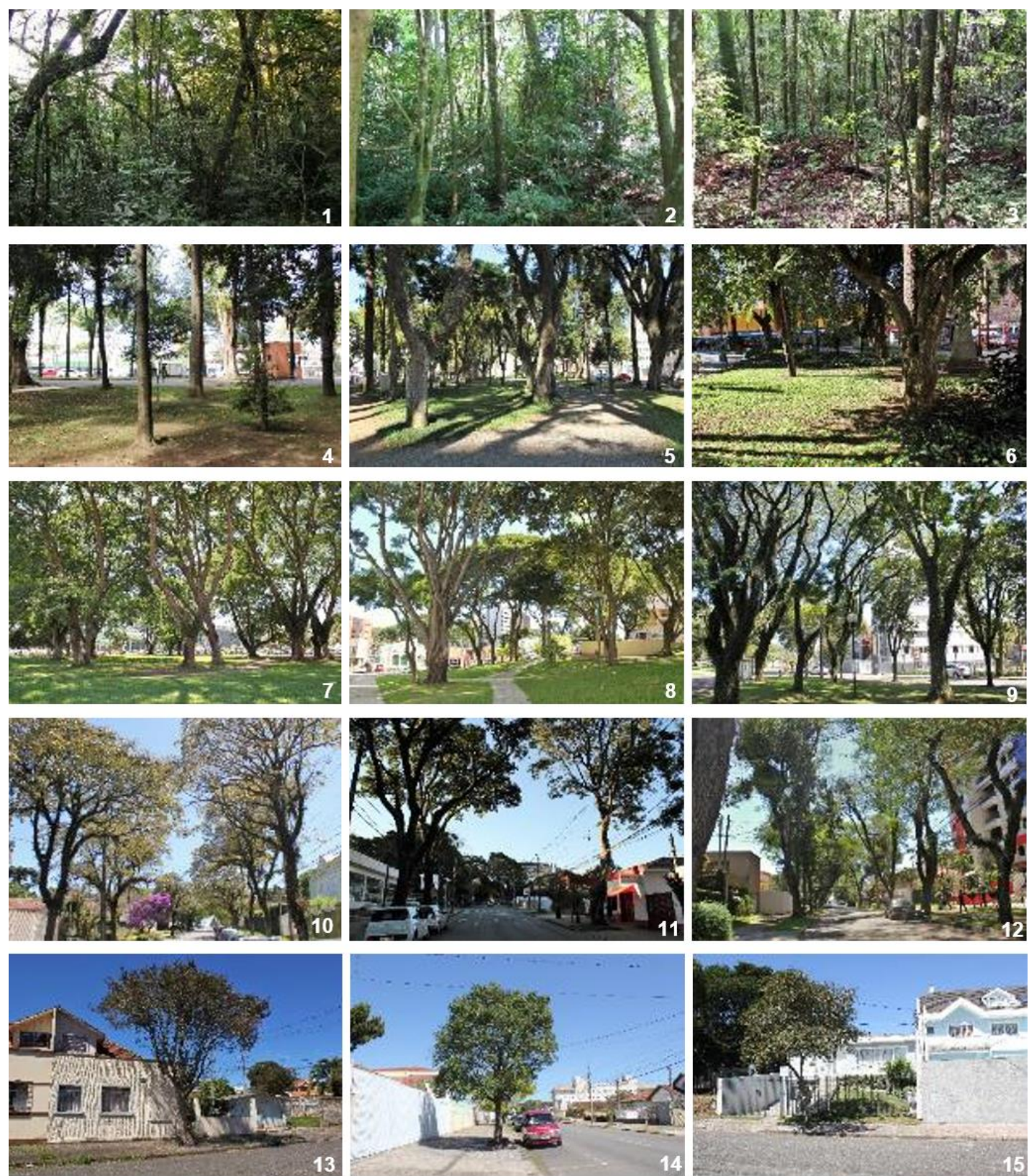

Nota: Remanescente Florestal: 1- Parque Barigüi; 2 - Bosque Gutierrez; 3 - Bosque João Paulo II; Área Verde Antiga: 4 - Passeio Público; 5 - Praça Eufrásio Correia; 6 - Praça Carlos Gomes; Área Verde Moderna: 7- Praça N. Sra. de Salette; 8 - Praça Alfredo Andersen; 9 - Jard. Henrique Knopholz; Arborização de Rua: 10 - Rua Brigadeiro Franco; 11- Rua Ângelo Lopes; 12 - Rua Guaratuba; Árvore Isolada: 13 - Lagerstroemia indica; 14 - Lafoensia pacari; 15 - Handroanthus chrysotrichus.

Figura 1. Áreas selecionadas para análise do microclima das diferentes tipologias de floresta urbana.

Figure 1. Selected areas for analysis of the microclimate of the different types of urban forest. 


\section{RESULTADOS}

A partir da determinação da média de temperatura e umidade relativa em cada tipologia de floresta urbana, foi possível observar não houve diferença estatística entre os blocos (locais selecionados) para nenhuma das variáveis (Tabela 1). Portanto, pode-se afirmar que as áreas escolhidas para representar as diferentes tipologias de floresta urbana são homogêneas, não se diferenciam entre si.

Tabela 1. Valores médios de temperatura e umidade relativa do ar em cada área selecionada e análise estatística das médias (SNK 95\%).

Table 1. Average values of temperature and relative humidity in each selected area and statistical analysis of means (SNK 95\%).

\begin{tabular}{|c|c|c|c|c|}
\hline Tipologias de Floresta Urbana & $\begin{array}{c}\text { Locais seleci } \\
1\end{array}$ & Locais selecionados & 3 & Média \\
\hline \multicolumn{5}{|c|}{ Temperatura média do $\operatorname{ar}\left({ }^{\circ} \mathrm{C}\right)$} \\
\hline Remanescente Florestal & 17,15 & 16,96 & 16,73 & $16,95 \mathbf{a}$ \\
\hline Área Verde Antiga & 17,82 & 17,99 & 17,96 & $17,93 \mathbf{b}$ \\
\hline Área Verde Moderna & 17,63 & 17,57 & 17,69 & $17,63 \mathbf{b}$ \\
\hline Arborização de Rua & 18,42 & 17,63 & 18,02 & $18,03 \mathbf{b}$ \\
\hline Árvore Isolada & 18,05 & 18,26 & 18,19 & $18,17 \mathbf{b}$ \\
\hline Média & $17,82 \mathbf{a}$ & $17,68 \mathbf{a}$ & $17,72 \mathbf{a}$ & \\
\hline \multicolumn{5}{|c|}{ Umidade Relativa do $\operatorname{Ar}(\%)$} \\
\hline Remanescente Florestal & 84,73 & 86,13 & 89,52 & $86,79 \mathbf{a}$ \\
\hline Área Verde Antiga & 78,17 & 77,40 & 76,50 & $77,36 \mathbf{b}$ \\
\hline Área Verde Moderna & 78,79 & 80,47 & 79,19 & $79,48 \mathbf{b}$ \\
\hline Arborização de Rua & 76,46 & 80,60 & 80,46 & $79,17 \mathbf{b}$ \\
\hline Árvore Isolada & 80,11 & 80,85 & 78,73 & $79,90 \mathbf{b}$ \\
\hline Média & $79,65 \mathbf{a}$ & $81,09 \mathbf{a}$ & $80,88 \mathbf{a}$ & \\
\hline
\end{tabular}

Nota: Remanescente Florestal: 1- Parque Barigüi; 2 - Bosque Gutierrez; 3 - Bosque João Paulo II; Área Verde Antiga: 1 - Passeio Público; 2 - Praça Eufrásio Correia; 3 - Praça Carlos Gomes; Área Verde Moderna: 1- Praça N. Sra. de Salette; 2 - Praça Alfredo Andersen; 3 - Jard. Henrique Knopholz; Arborização de Rua: 1 - Rua Brigadeiro Franco; 2- Rua Ângelo Lopes; 3 - Rua Guaratuba; Árvore Isolada: 1 Lagerstroemia indica; 2 - Lafoensia pacari; 3 - Handroanthus chrysotrichus. Médias seguidas de mesma letra na coluna ou linha não diferem entre si a 5\% de significância pelo teste SNK.

Tanto para a temperatura como para a umidade relativa, a análise estatística realizada revelou que apenas o Remanescente Florestal distingue-se estatisticamente das demais tipologias, pois apresenta a menor média de temperatura $\left(16,95^{\circ} \mathrm{C}\right)$ e a maior média de umidade relativa $(86,79 \%)$.

Embora sem diferença estatística para as demais áreas (exceto Remanescente Florestal), a tipologia Árvore Isolada foi a que apresentou maior média de temperatura $\left(18,16^{\circ} \mathrm{C}\right)$ e a tipologia Área Verde Antiga menor média de umidade relativa $(77,36 \%)$.

Ao analisar as médias encontradas separadamente para cada estação do ano é possível verificar algumas variações neste comportamento (Tabela 2).

Pode-se observar no verão que a análise estatística não demonstrou diferença entre o Remanescente Florestal $\left(21,34{ }^{\circ} \mathrm{C}\right)$ e a área Verde Moderna $\left(22,29{ }^{\circ} \mathrm{C}\right)$, mas apenas o Remanescente Florestal diferenciou-se de todas as outras tipologias, assim como ocorreu no inverno.

Para a variável temperatura não houve diferença entre os blocos (locais selecionados) em nenhuma estação, já para a umidade relativa, na estação do inverno, os locais selecionados 1 (maiores em área) diferenciaram-se das demais $(2,3)$, apresentando valor médio de umidade relativa inferior $(85,22 \%)$. Esse menor valor, deve-se à relação inversa com a temperatura, que nessas áreas, durante o inverno, foi maior.

No inverno, a umidade relativa também apresentou variação quanto às tipologias de floresta urbana, constatando-se que o Remanescente Florestal $(89,66 \%)$ e a Árvore Isolada (88,41\%) não se distinguem entre si, apresentando os maiores valores registrados de umidade relativa. Os menores valores foram observados na Área Verde Antiga (83,66\%) e na Área Verde Moderna (84,75\%).

Os valores de temperatura no verão foram quase o dobro do que os encontrados no inverno, o que proporciona significativa distinção entre as áreas, acentuando ainda mais as diferenças no verão, em média $1^{\circ} \mathrm{C}$ maior do que no inverno.

Apesar dos resultados demonstrarem que apenas o Remanescente Florestal diferencia-se das demais tipologias, percebe-se que todas exercem um papel fundamental na melhoria microclimática, pois a diferença para o remanescente foi pequena. A tipologia Árvore Isolada foi a que apresentou maior diferença de

FLORESTA, Curitiba, PR, v. 47, n. 2, p. 137 - 144, abr. / jun. 2017.

Martini, A. et al.

ISSN eletrônico 1982-4688

DOI: $10.5380 /$ rf.v47i1.49518 
temperatura $\left(1,22^{\circ} \mathrm{C}\right)$, seguida por Arborização de Rua $\left(1,08^{\circ} \mathrm{C}\right)$, Área Verde Antiga $\left(0,98^{\circ} \mathrm{C}\right)$ e Área Verde Moderna $\left(0,68^{\circ} \mathrm{C}\right)$. Já a Área Verde Antiga foi a que apresentou maior diferença de umidade relativa $(9,43$ unidades), seguida por Árvore Isolada (6,89 unidades), Arborização de Ruas (7,62 unidades) e Área Verde Moderna (7,31).

Tabela 2. Valores médios de temperatura e umidade relativa do ar em cada área selecionada e análise estatística das médias (SNK 95\%) no verão e no inverno.

Table 2. Average values of temperature and relative humidity in each selected area and statistical analysis of means (SNK 95\%) in summer and winter.

\begin{tabular}{|c|c|c|c|c|c|c|c|c|}
\hline \multirow{2}{*}{$\begin{array}{l}\text { Tipologias de Floresta } \\
\text { Urbana }\end{array}$} & \multicolumn{3}{|c|}{$\begin{array}{c}\text { Verão } \\
\text { Locais selecionados }\end{array}$} & \multirow{2}{*}{ Média } & \multicolumn{3}{|c|}{$\begin{array}{c}\text { Inverno } \\
\text { Locais selecionados } \\
\end{array}$} & \multirow{2}{*}{ Média } \\
\hline & 1 & 2 & $\mathbf{3}$ & & 1 & 2 & 3 & \\
\hline \multicolumn{9}{|c|}{ Temperatura média do $\operatorname{ar}\left({ }^{\circ} \mathrm{C}\right)$} \\
\hline Remanescente Florestal & 21,59 & 21,58 & 20,86 & $21,34 \mathrm{a}$ & 12,72 & 12,34 & 12,60 & $12,55 \mathrm{a}$ \\
\hline Área Verde Antiga & 22,48 & 22,82 & 22,70 & $22,67 \mathrm{~b}$ & 13,16 & 13,16 & 13,22 & $13,18 \mathrm{~b}$ \\
\hline Área Verde Moderna & 22,22 & 22,21 & 22,42 & $22,29 \mathrm{ab}$ & 13,04 & 12,93 & 12,95 & $12,98 \mathrm{~b}$ \\
\hline Arborização de Rua & 23,35 & 22,41 & 22,95 & $22,90 \mathrm{~b}$ & 13,49 & 12,86 & 13,09 & $13,15 \mathrm{~b}$ \\
\hline Árvore Isolada & 23,10 & 23,38 & 23,09 & $23,19 b$ & 12,99 & 13,14 & 13,30 & $13,14 b$ \\
\hline Média & $22,55 \mathrm{a}$ & $22,48 \mathrm{a}$ & $22,40 \mathrm{a}$ & & $13,08 \mathrm{a}$ & $12,89 \mathrm{a}$ & $13,03 \mathrm{a}$ & \\
\hline \multicolumn{9}{|c|}{ Umidade Relativa do $\mathrm{Ar}(\%)$} \\
\hline Remanescente Florestal & 82,48 & 80,34 & 88,96 & $83,93 \mathrm{a}$ & 86,98 & 91,92 & 90,08 & 89,66 a \\
\hline Área Verde Antiga & 70,82 & 71,47 & 70,87 & $71,05 \mathrm{~b}$ & 85,53 & 83,33 & 82,13 & $83,66 \mathrm{c}$ \\
\hline Área Verde Moderna & 74,94 & 75,92 & 71,79 & $74,22 \mathrm{~b}$ & 82,64 & 85,01 & 86,59 & $84,75 \mathrm{bc}$ \\
\hline Arborização de Rua & 69,14 & 74,58 & 73,01 & $72,25 \mathrm{~b}$ & 83,77 & 86,62 & 87,91 & $86,10 \mathrm{~b}$ \\
\hline Árvore Isolada & 73,06 & 69,79 & 71,31 & $71,39 \mathrm{~b}$ & 87,16 & 91,91 & 86,16 & 88,41 a \\
\hline Média & $74,09 \mathrm{a}$ & $74,42 \mathrm{a}$ & $75,19 \mathrm{a}$ & & $85,22 \mathrm{~b}$ & $87,76 \mathrm{a}$ & $86,57 \mathrm{a}$ & \\
\hline
\end{tabular}

Nota: Remanescente Florestal: 1- Parque Barigüi; 2 - Bosque Gutierrez; 3 - Bosque João Paulo II; Área Verde Antiga: 1 - Passeio Público; 2 - Praça Eufrásio Correia; 3 - Praça Carlos Gomes; Área Verde Moderna: 1- Praça N. Sra. de Salette; 2 - Praça Alfredo Andersen; 3 - Jard. Henrique Knopholz; Arborização de Rua: 1 - Rua Brigadeiro Franco; 2- Rua Ângelo Lopes; 3 - Rua Guaratuba; Árvore Isolada: 1 Lagerstroemia indica; 2 - Lafoensia pacari; 3 - Handroanthus chrysotrichus. Médias seguidas de mesma letra na coluna ou linha não diferem entre si a 5\% de significância pelo teste SNK.

\section{DISCUSSÃO}

O Remanescente Florestal foi a única tipologia que se distinguiu das demais, com menor média de temperatura e a maior média de umidade relativa. Dacanal et al. (2010), analisando diferentes fragmentos florestais urbanos em Campinas, também constataram que a vegetação densa e estratificada foi capaz de atenuar mais a temperatura do ar e interceptar a radiação solar, melhorando a sensação térmica local.

Para Hoffmann et al. (2010), o interior de formações florestais caracteriza-se pela estabilidade microclimática em comparação com as formações mais abertas. A principal razão para isso é a existência de diferentes estratos que separam as camadas de ar exterior à floresta (acima das copas) da camada de ar junto ao solo (sub-bosque). Além disso, há a existência de espécies caducifólias, que são especialmente funcionais, pois durante a época mais quente proporcionam sombra e durante o período mais frio, no qual perdem suas folhas, permitem a incidência dos raios solares, aquecendo o ambiente (OCHOA DE LA TORRE, 1999).

A tipologia Árvore Isolada foi a que apresentou maior média de temperatura, o que indica que o efeito de resfriamento das árvores isoladas não é muito significativo se comparado com o de uma floresta. Leal et al. (2013) também constatou que o efeito de árvores em agrupamento é bem maior do que em árvores isoladas. Ochoa de La Torre (1999) afirma que o efeito proporcionado por pequenos números de árvores desaparece rapidamente devido aos movimentos do ar, seja pelo vento ou pela convecção.

A análise das médias para cada estação do ano apontou algumas variações neste comportamento, sendo que no verão não houve diferença estatística entre o Remanescente Florestal e a área Verde Moderna. Essa semelhança entre as áreas deve-se a características da área verde moderna, quase em sua totalidade recoberta por área permeável e presença de indivíduos arbóreos de grande porte. Para Zhou et al. (2011), o uso e ocupação do solo, bem como a configuração das áreas verdes urbanas auxiliam no resfriamento, no entanto, é especialmente a presença de vegetação lenhosa que proporciona maiores diferenças de temperatura.

É importante lembrar, ainda, que a variável umidade relativa é mais difícil de ser compreendida, isto porque, segundo Fortuniak et al. (2006) o processo de saturação, as características da variação de umidade e os 
grandes erros de medição, tornam o problema de contraste do conteúdo de vapor d'água no ambiente urbano mais complexo do que para a temperatura. Além disso, as diferenças de umidade relativa do ar podem evoluir de diferentes maneiras sob sutis condições do tempo.

Por fim, os valores de temperatura no verão foram quase o dobro do que os encontrados no inverno, o que proporciona significativa distinção entre as áreas, acentuando ainda mais as diferenças no verão, em média $1{ }^{\circ} \mathrm{C}$ maior do que no inverno. Sabe-se, por exemplo, que a temperatura das áreas com vegetação tem efeito mais forte no resfriamento no verão do que no inverno (CHANG et al., 2007). Inclusive, a falta de vegetação pode causar a diminuição da temperatura no inverno, devido à facilidade com que os materiais de construção perdem calor para o meio, onde não existem barreiras naturais para detê-lo (AKBARI; TAHA, 1992). Além disso, a vegetação pode ainda bloquear ventos frios no inverno e/ou direcionar a entrada de correntes que resfriem o ambiente no verão (MAGALHÃES; CRISPIM, 2003).

\section{CONCLUSÕES}

Diante dos resultados obtidos pode-se concluir que:

- O microclima do Remanescente Florestal foi estatisticamente distinto das demais tipologias, apresentando a menor média de temperatura e a maior média de umidade relativa;

- A Árvore Isolada foi a tipologia que apresentou maior média de temperatura e a Área Verde Antiga a menor média de umidade relativa;

- Embora, estatisticamente distintas, a diferença média de temperatura entre as tipologias foi inferior a $1^{\circ} \mathrm{C}$;

- Os resultados encontrados enfatizam a importância da floresta urbana, em todas as suas formas (tipologias) para a melhoria do microclima da cidade de Curitiba.

\section{AGRADECIMENTOS}

À Fundação Araucária de Apoio ao Desenvolvimento Científico e Tecnológico do Paraná pelo financiamento à compra dos equipamentos.

\section{REFERÊNCIAS}

ADAMS, M. P.; SMITH, P. L. A systematic approach to model the influence of the type and density of vegetation cover on urban heat using remote sensing. Landscape and Urban Planning, Amsterdã, v. 132, p. 47$54,2014$.

AKBARI, H.; TAHA, H. Impact of trees and white surfaces on residential heating and cooling energy use in four Canadian cities. Energy, Oxford, v. 17, n. 2, p. 141-149, 1992.

AlVARES, C. A.; STAPE, J. L.; SENTElhas, P. C.; DE MORAES GONÇALVES, J. L., SPAROVEK, G. Köppen's climate classification map for Brazil. Meteorologische Zeitschrift, Stuttgart, v. 22, n. 6, p. 711-718, 2014.

ARAÚJO, L. H. B. de; NÓBREGA, C. C. da; SILVA, A. C. F. da; VIEIRA, F. de A. Análise quali-quantitativa da arborização da Praça Pedro Velho, Natal, RN. Agropecuária Científica no Semi-Árido, Patos - PB, v. 11, n. 1, p. 65-71, 2015.

BASSO, J. M.; CORRÊA, R. S. Arborização urbana e qualificação da paisagem. Paisagem e Ambiente, São Paulo, n. 34, p. 129-148, 2014.

BROWN, R. D.; VANOS, J.; KENNY, N.; LENZHOLZER, S. Designing urban parks that ameliorate the effects of climate change. Landscape and Urban Planning, Amsterdã, v. 138, p. 118-131, 2015.

CHANG, C.; LI, M.; CHANG, S. A preliminary study on the local cool-island intensity of Taipei city parks. Landscape and Urban Planning, Amsterdã, v. 80, p. 386-395, 2007.

CHEN, A.; YAO, X. A.; SUN, R.; CHEN, L. Effect of urban green patterns on surface urban cool islands and its seasonal variations. Urban Forestry \& Urban Greening, Amsterdã, v. 13, p. 646-654, 2014.

DACANAL, C.; LABAKI, L. C.; SILVA, T. M. L. Vamos passear na floresta! O conforto térmico em fragmentos florestais urbanos. Ambiente Construído, Porto Alegre, v. 10, n. 2, p. 115-132, 2010. 
FORTUNIAK, K.; KLYSIK, K.; WIBIG, J. Urban-rural contrasts of meteorological parameters in Lodz. Theoretical and Applied Climatology, Viena, v. 84, p. 91-101, 2006.

HEINL, M.; HAMMERLE, A.; TAPPEINER, U.; LEITINGER, G. Determinants of urban-rural land surface temperature differences - A landscape scale perspective. Landscape and Urban Planning, Amsterdã, v. 134, p. 33-42, 2015.

HOFFMANN, G. S.; HASENACK, H.; OLIVEIRA, L. F. B. Microclima e estruturas de formações vegetais. In: SESC. O clima na Reserva Particular de Patrimônio Natural SESC Pantanal. Rio de Janeiro: SESC, 2010. p. 11-53.

JIANG, B.; LARSEN, L.; DEAL, B.; SULLIVAN, W. C. A dose-response curve describing the relationship between tree cover density and landscape preference. Landscape and Urban Planning, Amsterdã, v. 139, p. 16-25, 2015.

JIANG, B.; CHANG, C. Y.; SUlLIVAN, W. C. A dose of nature: Tree cover, stress reduction, and gender diferences. Landscape and Urban Planning, Amsterdã, v. 132, p. 26-36, 2014.

JIM, C. Y.; LO, A. Y.; BYRNE, J. A. Charting the green and climate-adaptive city. Landscape and Urban Planning, Amsterdã, v. 138, p. 51-53, 2015.

KONG, F.; YIN, H.; WANG, C.; CAVAN, G.; JAMES, P. A satellite image-based analysis of factors contributing to the green-space cool island intensity on a city scale. Urban Forestry \& Urban Greening, Amsterdã, v. 13, p. 846-853, 2014.

LEAL, L.; AlMEIDA, A. M. R. de; BIONDI, D.; LIMA NETO, E. M. de; MARTINI, A. Microclima de tipologias paisagísticas do Parque Municipal Tingui, Curitiba, Paraná. Revista Geografar, Curitiba, v. 9, n. 1, p. 8-26, 2014.

LEAL, L.; BIONDI, D.; BATISTA, A. C. Classificação de unidades microclimáticas no período de resfriamento noturno na área intraurbana de Curitiba, Paraná. Acta Geográfica, Boa Vista, v. 9, n. 21, p. 161-177, 2015.

MAGALHÃES, L. M. S.; CRISPIM, A. A. Vale a pena plantar e manter árvores e florestas na cidade? Ciência Hoje, Rio de Janeiro, v. 33, n. 193, p. 64-68, 2003.

OCHOA DE LA TORRE, J. M. La vegetación como instrumento para el control microclimático en línea. 1999. Não paginado. Tesis (Doctor en Arquitectura) - Escola Tècnica Superior d'Arquitectura de Barcelona, Universidad Politécnica de Cataluña, 1999.

RASKOVI, S.; DECKER, R. The influence of trees on the perception of urban squares. Urban Forestry \& Urban Greening, Amsterdã, v. 14, p. 237-245, 2015.

SHASHUA-BAR, L.; POTCHTER, O.; BITAN, A.; BOLTANSKY, D.; YAAKOV, Y. Microclimate modelling of street tree species effects within the varied urban morphology in the Mediterranean city of Tel Aviv, Israel. International Journal of Climatology, Reading - UK, v. 30, p. 44-57, 2010.

YU, C.; HIEN, W. N. Thermal benefits of city parks. Energy and Buildings, Lausanne, v. 38, p. 105-120, 2006.

ZHOU, W.; HUANG, G.; CADENASSO, M. L. Does spatial configuration matter? Understanding the effects of land cover pattern on land surface temperature in urban landscapes. Landscape and Urban Planning, Amsterdã, v. 102, p. 54-63, 2011. 